Yayın Geliş Tarihi: 12.02.2014

Yayına Kabul Tarihi: 30.04 .2015

Online Yayın Tarihi: 31.08.2015

http://dx.doi.org/10.16953/deusbed.98286
Dokuz Eylül Üniversitesi

Sosyal Bilimler Enstitüsü Dergisi

Cilt: 17, Say1: 1, Y11: 2015, Sayfa: 105-118

ISSN: 1302-3284 E-ISSN: 1308-0911

\title{
ORTAKLIK YAPILARININ FINANSMAN KARARLARI ÜZERİNE ETKİSİ: BIST ENERJİ FİRMALARI İNCELEMESİ
}

\author{
F. Dilvin TAŞKIN ${ }^{*}$ \\ Sedat COŞKUN ${ }^{* *}$ \\ $\ddot{O} z$
}

Modigliani ve Miller'dan (1958) sonra iflas maliyeti, temsilci maliyetleri, bilgi farklllikları ve vergi konularına dayanarak firmaları optimal sermaye yapısinı ne şekilde oluşturacakları finans literatüründe çokça incelenmiştir. Bu çalışmada da amaç, 20082012 ylllarında Borsa İstanbul'da işlem gören ve faaliyet konusu enerji olan firmaların sermaye yapısına etki eden faktörleri incelemektir. Bu amaçla finansal kaldıracın açılklayıcı değişkenleri olarak karlllık, teminat değeri, büyüme, borç dışı vergi kalkanl, firmanın farklllı̆̆ ve bunların yanında ortaklık yapısı özelliklerinin etkisi panel regresyon yöntemi ile incelenmiştir. Çalı̧̧manın sonuçlarına göre en büyük hissedar payı ve halka açıklık oranı ile ölçülen ortaklık yapısının finansal kaldıraç üzerinde dikkate değer bir etkisi olduğu, bunun yanında teminat değeri, borç dışı vergi kalkanı ve firma büyüklü̆ü̈nün borçları pozitif yönde etkilerken, firma farklılı̆̆ ve karlılık oranının borçların kullanımında azalmaya neden olduğu görülmüştür.

Anahtar Kelimeler: Sermaye Yapısl, Finansman Kararlarl, Ortaklık Yapısl.

\section{THE IMPACT OF OWNERSHIP STRUCTURE ON THE FINANCING DECISIONS: EVIDENCE FROM BIST ENERGY COMPANIES}

\section{Abstract}

Following Modigliani and Miller (1958) finance literature widely analyzed how the firm chooses its optimal capital structure based on bankruptcy costs, agency costs, information asymmetries and tax. The aim of this paper is to analyze the factors that affect the capital structure of the companies that are traded in Borsa Istanbul and with the main area of activity is energy for the period 2008 and 2012. For this reason, profitability, collateral value, growth, non-debt tax shield, uniqueness and besides the impact of ownership structure are analyzed as determinants of financial leverage through the use of panel regression analysis. According to the results of the analyses, the ownership structure, that is proxied by the share of the biggest shareholder and free float rate, has significant effects on financial leverage and moreover collateral value, non-debt tax shield and firm size has positive, uniqueness and profitability ratio has negative effects on the debts of the company.

Keywords: Capital Structure, Financing Decisions, Ownership Structure.

\footnotetext{
* Doç. Dr., Yaşar Üniversitesi, İktisadi ve İdari Bilimler Fakültesi, İşletme Bölümü, dilvin.taskin@yasar.edu.tr

** Öğr. Gör., Celal Bayar Üniversitesi, Kula Meslek Yüksek Okulu, sck-023@hotmail.com
} 
Tașkin, D., Coșkun, S.

DEÜ SBE Dergisi, Cilt: 17, Sayl: 1

\section{GİRIŞ}

İşletmeler artan rekabet koşulları ve yeni yatırımlar nedeniyle daha çok sermayeye ihtiyaç duymaktadır. İşletmelerin sermaye yapıları da bulundukları sektöre ya da firmanın ihtiyaçlarına göre değişiklik göstermektedir. Bunun yanında, işletmelerin ortaklık yapıları da sermaye yapılarını etkileyebilmektedir. Ortaklık yapısı, hissedar sayısı, hissedarların sahip oldukları hisse oranları ya da işletmenin halka açıklık oranına ilişkin kavramları akla getirmektedir. İşletmelerde ortak sayısının fazlalı̆̆ı, sahipliğin tabana yayıldığına işaret ederken, bu durum finansal piyasaların temel işlevlerinden birisidir. Amaçlanan, ortak sayısını mümkün olduğunca arttırıp ortaklık yapısını derinleştirmektir.

İşletmelerin finansman kararları bir finansman yöneticisi açısından en hayati kararlardan birisi olmaktadır. Sermaye yapısının biçimlendirilmesi şirketlerin karlılığının kaldıracı olduğu gibi, şirketleri iflasa kadar sürükleyen bir zinciri de hareket ettirmektedir. Aktiflerin borçlarla finanse edildiği durumlarda, bu yükümlülükler vadesi geldiğinde karşılanması gerekirken, hisse senedi ihracı da son derece maliyetli olmaktadır. Dolayısıyla sermaye yapısı kararları likiditefaaliyet riski ile kar arasında optimal bir noktada olmayı gerektirmektedir (Sayılgan ve Sayman, 2009: 2).

Modigliani ve Miller (1958) firma değerinin finansman kararından bağımsız olduğu görüşünü ortaya attıklarından beri finansman kararlarının firma değeri ve firma performansı üzerinde ne derece etkisi olduğu çokça sorgulanan bir konu haline gelmiştir. Modigliani ve Miller bu savın, tam rekabet koşullarında, firma çalışanlarının ve üçüncü kişilerin simetrik bilgiye sahip olduğu, işlem maliyetlerinin ve iflas maliyetlerinin olmadığı koşullar altında geçerli olduğunu iddia etmiştir. Ancak söz konusu varsayımların gerçekçi olmaması araştırmacıları finansman kararlarının etkileri üzerinde farklı yaklaşımlar geliştirmelerine neden olmuştur.

Ödünleşme teorisi, firma değerini maksimize ederken; iflas maliyeti, hissedarlar ve borç verenler arasındaki vekâlet maliyetini en aza indirgeyen bir borç/sermaye oranının olduğunu ve firmanın bu orana ulaşmak için çabaladığını öne sürmektedir (Myers, 1984). Dolayısı ile firmanın hedef kaldıraç oranı firmanın borç vergi kalkanından yararlandığı ve mali sıkıntıya düşmeyeceği noktada olmalidir.

Finansman hiyerarşisi teorisine göre, firmalar finansman ihtiyac1 duyduklarında öncelikle dağıtılmamış karlara, ardından borçlara yönelmekte, en son olarak ise hisse senedi ihraç etmektedir (Myers ve Majluf, 1984; Myers, 1984).

Jensen ve Meckling'in (1976) savunduğu vekalet teorisine göre optimum sermaye yapısı hem borç, hem de hisse ihraçlarının neden olacağ 1 vekalet maliyetlerine göre belirlenmektedir. Hisse ihracına ilişkin maliyetler, hissedarların gözetilmesine ilişkin giderler, yöneticilerin firmaya bağlanması için yapılan giderler ve yöneticilerin hissedarlardan ayrışmasından kaynaklı artık giderlerden 
oluşmaktadır. Borç ihraçları ise yöneticilere hissedarlar için getirisi daha yüksek ancak daha riskli projelere yatırım yapma imkânı tanırken, tahvil sahiplerine başarısızlık durumunda paylaşmak zorunda kaldıkları kayıplara neden olmaktadır. Borç verenler bu durumu fark ettikleri durumlarda daha yüksek risk primi isteyecekler ve bu da borçlanmanın maliyetini arttıracaktır. Bu durumda firmanın borçlanma ve hisse ihraçlarının vekalet maliyetlerini azaltıcı optimal bir sermaye yapısında karar kılması gerekmektedir.

$\mathrm{Bu}$ çalışmada amaç bu önemli kararın küresel kriz sonrasında Borsa İstanbul'da işlem gören enerji şirketleri tarafindan nasıl verildiğini analiz etmek ve bu firmalardaki sermaye yapısını etkileyen faktörleri incelemektir. Diğer birçok çalışmadan farklı olarak ortaklık yapısının bu kararlar üzerinde belirleyici bir etkisinin olup olmadığını incelemek de çalışmanın bir diğer motivasyonunu oluşturmaktadır. Çalışmanın 2. Bölümünde bu alanda yapılan literatür sunulacak, 3. Bölümde veri seti ve yöntem açıklanacak, 4. Bölümde analiz sonuçları sunulup 5. Bölümde ise sonuç ve değerlendirmelere yer verilecektir.

\section{LITERATÜR TARAMASI}

Firmaların sahiplik yapısı ve sermaye yapısının firma performansını etkilediği fikri ilgi çekse de sahiplik yapısı- sermaye yapısı ilişkisine Brailsford vd.'ne (2002) kadar bu konuyu detaylı bir şekilde inceleyen çalışma sayısı oldukça sınırlıdır. Önceki çalışmalar daha çok sermaye yapısı ve firma değeri/karlılık ilişkilerine odaklanırken, Brailsford vd. (2002) sahipliğin yöneticilere yayılması ve blok hissedarların varlığı firmaların kaldıraç düzeyinde etki ettiği varsayımıyla hareket etmişlerdir. Blok hissedarların varlığının firmanın yükümlülük düzeyini anlamlı bir şekilde arttırdığı gözlenirken, yöneticilerin sahiplik yüzdesi ve kaldıraç arasında doğrusal olmayan, U-şeklinde bir ilişki tespit edilmiştir.

Sermaye yapısını şirket yönetiminin büyüme stratejileri, kısa ve uzun dönemli hedefleri, şirket yönetiminin karlılık-risk arasındaki tercihi, yatırımcı tercihleri, yatırımların büyüklüğü ve teknoloji yoğun-sermaye yoğun olması gibi çeşitli birçok faktör tarafindan şekillendirilmektedir (Sayılgan ve Sayman, 2009: $3)$. $\mathrm{Bu}$ nedenle yöneticiler tarafindan bu değişkenlerin bilinmesi işletmelerin performanslarına etkileri hakkında bilgi sağlanması açısından önem arz etmektedir. Nitekim işletme çoğunluk payına sahip olan ortak sayısı, halka açıklık oranı, toplam özkaynaktaki yabancı payı, işletmenin kurumsal veya aile bazında yönetilmesi, ortaklık ve yönetimin aynı kişilerde toplanması gibi mülkiyet yapısını şekillendiren etmenlerin de performans üzerinde ne derecede ve nasıl etkili olduğu bilinmesi gerekmektedir (Bayrakdaroğlu, 2010: 2).

Driffield vd. (2007) krizlerden en çok etkilenen 4 Uzakdoğu ülkesiniEndonezya, Kore, Malezya ve Tayland- kapsayan çalışmalarında sahiplik yapısının, sermaye yapısı ve firma değeri üzerindeki etkilerini incelemişlerdir. Bu etkileri incelerken en büyük beş hissedarın toplam sermaye içindeki payını 
mülkiyet yoğunlaşması olarak tanımlamışlardır. Çalışmada en büyük sermaye payına sahip ortağın nakit akışları üzerindeki kontrolü de dikkate alınmıştır. Mülkiyet haklarının büyük ortak ya da ortakların elinde yoğunlaşması, borçlanmaya dayalı (sermaye yapısını borca ağırlık vererek değiştiren) bir sermaye yapısı ile sonuçlanmaktadır. Çalışmada kullanılan kontrol değişkenleri; şirket büyüklüğü, şirket yaşı, yatırım ve büyüme olanakları, varlık çeşitlendirmesi olarak sıralanmaktadır Araştırma sonuçlarına göre, ortaklık yapısındaki yoğunlaşma arttıkça, borçluluk oranı da artmaktadır. Dolayısı ile ortaklık yapısının yoğunlaşması, büyük ortakların bu durumu korumak amacıyla borçlanmaya dayalı büyüme stratejisi benimsedikleri ve daha fazla kar için risk iştahının arttığı savı ampirik olarak doğrulanmıştır.

Bununla birlikte, Cespedes vd. (2010) tarafından yapılan çalışmada Latin Amerika ülkelerinin sermaye yapılarının belirleyicilerini araştırdıkları çalışmanın sonuçlarına göre, yüksek Herfindahl endeksine sahip, diğer bir ifade ile yüksek sermaye yoğunluğu olan işletmelerde sermaye yapılarının yabancı kaynak ağırlıklı olduğu tespit edilmiştir. Mehran vd. (1999) tarafindan yapılan çalışmada yönetici (CEO) sahipliğinin, şirketlerin sermaye yapısı kararları üzerindeki etkisi, finansal sözleşme teorisine dayandırılarak incelenmiştir. Finansal sözleşme teorisi, işletmenin faaliyet risklerinin ve işletme için yatırım firsatlarının varlığının sözleşme maliyetlerini etkilediğini, dolayısıyla firmalar satın almaktan çok finansal kiralamaya eğildiklerini ifade etmektedir. Çalışma sonuçlarına göre yönetici sahipliğinin sermaye yapısı üzerinde anlamlı ve pozitif bir etkisi olduğu, diğer bir ifade ile hisse senetleri içindeki yönetici payı arttıkça işletmelerin daha fazla yabancı kaynak kullanacakları sonucu ulaşılmıştır. Yönetici sahipliği arttıkça, finansal kiralama ve borç yüklenimi oranı artmakta, yöneticiler değer yitirme, tükenme gibi aktiflere dayalı risklerini azaltmak için dış kaynak kullanımına daha yatkın oldukları görülmüştür.

Li vd. (2009) tarafindan Çin'de faaliyet gösteren şirketlerin sahiplik yapılarının incelendiği çalışmada kamu sahipliğ̣i, yabancı sahipliği ve kurumsal yatırımcı sahipliği kukla değişkenleri kullanılarak sermaye yapısının bu etkenlerden etkilenip etkilenmediği araştırılmıştır. Kamu sahipliği, kaldıraç ve uzun dönemli finansman kaynaklarına erişimle pozitif ilişkili bulunurken, kamu sahipliği olmayan firmaların kısa dönemli yükümlülüklerinin ve toplam borçlarının, kamu şirketlerinden anlamlı oranda az olduğu tespit edilmiştir. Çalışma, sahiplik yapısı kombinasyonlarının, firmaların kaldıraç kullanım kararındaki varyasyonların \%6'sını tek başına açıkladığına da dikkat çekmiştir.

Pushner (1995) tarafindan yapılan çalışmada Japonya'da kurumsal yatırımcı sahipliğinin şirketin sermaye yapısı üzerindeki etkisi incelenmiştir. Buna göre, kurumsal yatırımcıların sahip olduğu şirketlerin diğer şirketlere göre sermaye yapılarını daha az yabancı kaynak kullanarak finanse etmeyi tercih etmekte olduğu sonucuna ulaşılmıştır. Çalışmada bağımlı değişken olarak toplam yabancı kaynakların toplam kaynaklara oranı kullanılmış olup, kurumsal yatırımcı, yönetici 
ve yatırımcı şirket sahipliği oranının toplam sermayeye oranı incelenmiştir. Çalışmada dikkat çeken bir diğer konu da kurumsal yatırımcıların, bu firmalarda hissedar olmanın yanında, aynı zamanda borç veren olduğunun da bildirilmesidir. Sonuç olarak, Japonya'da hem sahiplik yapısının, sahiplik yapısında kurumsal yatırımcı oranının, hem de temsilci maliyetlerinin sermaye yapısını anlamlı bir şekilde etkilediği görülmüştür.

Sayılgan vd. (2006), İMKB'de faaliyet göstermekte olan 123 imalat firmasını inceledikleri çalışmada, bu firmaların sermaye yapısına etki eden değişkenlerin - işletme büyüklüğü, kârlılık, aktiflerin büyüme oranı, duran varlık oranı ve borç dışı vergi kalkanı- üzerine odaklanmışlardır. Çalışmanın sonuçlarına göre işletme büyüklüğü ve aktiflerin büyüme firsatları borçlarda anlamlı artışa yol açmaktadır. Öte yandan, karlılık, duran varlıklardaki büyüme borç dışı vergi kalkanı kaldıraç oranını zıt yönde etkilemektedir. Durukan (1997) da benzer şekilde 1990-1995 döneminde faaliyet gösteren 68 firmayı incelediği araştırmada karlılık ve borç dışı vergi kalkanının sermaye yapısını etkileyen en önemli faktörler olduğunu vurgulamıştır. Vergi oranının da sermaye yapısına anlamlı düzeyde etki eden bir unsur olduğu çalışmanın bir diğer bulgusudur.

Akkum'un (1998) İMKB'de 1988 ile 1996 yıllarında faaliyet gösteren şirketlerin karlılıklarıyla sermaye yapısı arasındaki ilişkinin tespitine yönelik yapmış olduğu çalışma 1996 ve 1995 yıllarında karlılıkla sermaye yapısı arasında anlamlı düzeyde negatif yönde bir ilişki olduğu bulgulanmıştır.

Sayılgan ve Uysal'in (2011) daha güncel verilerle 1996-2008 dönemini Türkiye Cumhuriyet Merkez Bankası sektör bilançoları üzerinden analiz ettikleri çalışma da benzer şekilde borç dışı vergi kalkanı ve borçlanma arasında negatif ilişki olduğunu; büyüme firsatları, büyüklük, karlılık ve varlık yapısının borçlanmayı pozitif etkilediğini raporlamışlardır. Yapılan çalışmalara bakıldığında çalışmaların daha çok imalat sektörü üzerinde yoğunlaştığı, ya da tüm sektörlere odaklandığı görülürken, sektör bazında değerlendirmelere rastlanamamıştır. Çalışma, her geçen gün önemi daha da artan enerji sektörü üzerine yoğunlaşması bakımından diğer çalışmalardan ayrışmaktadır.

\section{VERİ SETİ VE YÖNTEM}

Çalışmada, Borsa İstanbul faaliyet alanı enerji olan 12 firmanın 2008-2012 yılları arasında ortaklık yapılarının finansman kararlarına etkisini incelenmektedir. $\mathrm{Bu}$ amaçla mali tablolarına ve dipnotlarına ilişkin veriler Kamuyu Aydınlatma Platformu'ndan (http://www.kap.gov.tr), ortaklık yapısına ilişkin verilerin bir kısmı ise kendi web sayfaları ve bilanço dipnotlarından derlenmiştir. Firmalar ve aktif büyüklüklerine ilişkin bilgi Ek 1'de sunulmaktadır.

Şirketlerin finansman kararları dendiğinde, varlıkların finansmanında kullanılan kaynakların bileşimi yani sermaye yapısı kastedilmektedir (Sayılgan ve Sayman, 2009: 2). Çalışmada sermaye yapısının bileşimi ölçmek için finansal 
kaldıraç oranı dikkate alınmıştır. Finansal kaldıraç oranı, toplam borçların toplam varlıklara oranı olarak incelendiği gibi (TB/TV), uzun vadeli yükümlülüklerin toplam varlıklara oranı (UVY/TV) ve kısa vadeli yükümlülüklerin toplam varlıklara oranı (KVY/TV) şeklinde de incelenmiştir.

Sermaye yapısının belirleyicileri olarak karlılık, teminat değeri, büyüme, borç dışı vergi kalkanı, firmanın farklılığı ve kontrol değişkeni olarak da firma büyüklügü incelenmiştir.

Firmanın karlılığının sermaye yapısına etkisinin ne yönde olduğu literatürde henüz netliğe kavuşturulabilmiş değildir. Finansman hiyerarşi teorisine göre firmalar öncelikle kendi finansman kaynaklarına yönelecekler, ardından yabancı kaynak arayışına gireceklerdir. Dolayısı ile bu teoriye göre finansal kaldıraç ile karlılık arasında negatif yönlü bir ilişki beklenmektedir. Diğer yandan ödünleşme teorisine göre, daha karlı firmaların vergi muafiyeti sağlaması nedeni ile diğer kaynaklardan ziyade borçlara yöneldiği düşünülmektedir. Buradan hareketle karlılık ile finansal kaldıraç arasında pozitif yönlü bir ilişki olacağ 1 varsayılmaktadır. Çalışmada firma karlılığı net karın toplam satışlara oranı (NK/TS) ve net karın toplam aktiflere oranı (NK/TA) ile ölçülmüştür.

Hissedarlar ve borç verenler arasında menfaat çatışmaları olabileceğinden, borç verenler kendilerinin güvence altına alacak teminatlar aramaktadırlar. Teminat olarak da duran varlıklar gösterilebilmektedir. Dolayısı ile yüksek miktarda duran varlığa sahip olan firmalar daha yüksek miktarda teminat gösterebilmektedir. Dolayısı ile teminat miktarı ve kaldıraç arasında pozitif yönlü bir ilişkisi olması beklenmektedir. Teminat ölçüsü olarak da duran varlıkların toplam aktiflere oranı (DV/TA) kullanılmıştır.

Büyüme potansiyeli fazla olan firmaların dış kaynak ihtiyacının daha fazla olduğu düşünülmektedir. Rajan ve Zingales (1995) de büyüme ve finansal kaldıraç arasında aynı yönlü anlamlı bir ilişki bulunduğunu tespit etmişlerdir. Büyüme potansiyeli göstergesi olarak toplam aktiflerdeki yüzdesel değişim (AB) ve satışlardaki yüzdesel artış (SB) seçilmiştir.

Faiz ödemelerinin vergiden muaf olması firmalar için borçları cazip hale getirmektedir. Borçlanmanın vergi avantajını ölçmek için literatürde borç dışı vergi kalkanı kavramına yer verilmiştir (DeAngelo ve Masulis, 1980). Borç dış1 vergi kalkanı büyük olan bir firma daha az borçlanma eğiliminde olacağından, bu oranın büyük olduğu firmalarda kaldıraç oranı daha az olacaktır. Amortismanların toplam aktiflere oranı (BDVK) borç dışı vergi kalkanını temsilen kullanılmıştır.

Firmalar, araştırma geliştirme faaliyetleri ile kendilerini ve ürünlerini diğer rakiplerden farklılaştırabilir. Titman (1984) ile Titman ve Wessels (1988) araştırma geliştirme faaliyetleri sonucunda ürün farklılaştırmasına giden firmaların daha düşük borç oranlarına sahip olduğu sonucuna ulaşmıştır. Firma farklılığını (FF) ölçmek için de bu çalışmada araştırma geliştirme giderlerinin toplam satışlara oranı baz alınmıştır. 
Firmanın ortaklık yapısını analiz etmek için firmanın halka açıklık oranı (HAO) ve en büyük hissedarın toplam hisseler içindeki payı dikkate alınmıştır.

Firmaların büyüklüğ̈nü kontrol etmek için ise toplam varlıkların doğal logaritması hesaplanmıştır. Verilere ilişkin özet açılamalar ve tanımlayıcı istatistikler Tablo 1'de sunulmaktadır.

Tablo 1: Çalışmada Kullanılan Değişkenlere İlişkin Özet Bilgiler

\begin{tabular}{|c|c|c|c|c|c|}
\hline Değişken & Kisaltma & Ortalama & $\begin{array}{l}\text { Std. } \\
\text { Sapma }\end{array}$ & \begin{tabular}{|l} 
Gözlem \\
Sayısı
\end{tabular} & Açıklama \\
\hline \multirow[t]{3}{*}{$\begin{array}{l}\text { Finansal } \\
\text { Kaldıraç }\end{array}$} & $\mathrm{TB} / \mathrm{TV}$ & 0.4634 & 0.2753 & 53 & $\begin{array}{l}\text { Toplam Borçların Toplam Varlıklara } \\
\text { Oranı }\end{array}$ \\
\hline & UVY/TV & 0.2407 & 0.2073 & 53 & $\begin{array}{l}\text { Uzun Vadeli Yükümlülüklerin } \\
\text { Toplam Varlıklara Oranı }\end{array}$ \\
\hline & KVY/TV & 0.2227 & 0.1508 & 53 & $\begin{array}{l}\text { Kısa Vadeli Yükümlülüklerin Toplam } \\
\text { Varlıklara Oranı }\end{array}$ \\
\hline $\begin{array}{l}\text { En Büyük } \\
\text { Hissedar }\end{array}$ & EBH & 0.5510 & 0.1775 & 53 & $\begin{array}{l}\text { En büyük Hissedarın Hisse } \\
\text { Toplamının Tüm Hisselere Oranı }\end{array}$ \\
\hline \begin{tabular}{|l} 
Halka \\
Açıklık \\
Oranı
\end{tabular} & HAO & 0.3261 & 0.1916 & 53 & $\begin{array}{l}\text { Firmanın halka sunulmuş hisselerinin } \\
\text { tüm hisselere oranı }\end{array}$ \\
\hline \multirow[t]{2}{*}{ Karlil1k } & $\mathrm{NK} / \mathrm{TS}$ & 0.5954 & 212.76 & 53 & $\begin{array}{l}\text { Net kar Marjı, Net Dönem Karının } \\
\text { Satışlara Oranı }\end{array}$ \\
\hline & NK/TA & 0.0529 & 0.0841 & 53 & $\begin{array}{l}\text { Net Dönem Karının Toplam Aktiflere } \\
\text { Oranı }\end{array}$ \\
\hline Teminat & DV/TA & 0.3461 & 0.2391 & 53 & $\begin{array}{l}\text { Duran Varlıkların Toplam Aktiflere } \\
\text { Oranı }\end{array}$ \\
\hline \multirow[t]{2}{*}{ Büyüme } & $\mathrm{AB}$ & 0.2088 & 0.2897 & 53 & $\begin{array}{l}\text { Aktiflerde Bir Önceki Seneye Göre } \\
\text { Yüzdesel Büyüme }\end{array}$ \\
\hline & SB & 0.4774 & 2.2129 & 53 & $\begin{array}{l}\text { Satışlardaki Bir Önceki Seneye Göre } \\
\text { Yüzdesel Büyüme }\end{array}$ \\
\hline \begin{tabular}{|l} 
Borç Diş1 \\
Vergi \\
Kalkanı
\end{tabular} & BDVK & 0.0540 & 0.1348 & 53 & $\begin{array}{l}\text { Amortismanların Toplam Aktiflere } \\
\text { Oranı }\end{array}$ \\
\hline \begin{tabular}{|l|} 
Firma \\
Farklılığ1
\end{tabular} & FF & 0.0069 & 0.0398 & 53 & $\begin{array}{l}\text { Araştırma Geliştirme Giderlerinin } \\
\text { Toplam Satışlar İçindeki Payı }\end{array}$ \\
\hline $\begin{array}{l}\text { Firma } \\
\text { Büyüklüğü }\end{array}$ & FB & 14.235 & 1.5173 & 53 & Aktiflerin Doğal Logaritması \\
\hline
\end{tabular}

Çalışmada panel regresyon yöntemi ile t zamanında i firmasının finansman kararını etkileyen değişkenlerin analizi belirtilen modeller aracılı̆̆ ile gerçekleştirilmiştir:

$$
\begin{aligned}
& \left(\frac{T B}{T V}\right)_{i, t}=\alpha_{t}+E B H_{i, t}+H A O_{i, t}+\left(\frac{N K}{T S}\right)_{i, t}+\left(\frac{D V}{T A}\right)_{i, t}+A B_{i, t}+B D V K_{i, t}+F F_{i, t}+ \\
& F B_{i, t}+\varepsilon_{i, t}(1) \\
& \left(\frac{T B}{T V}\right)_{i, t}=\alpha_{t}+E B H_{i, t}+H A O_{i, t}+\left(\frac{N K}{T A}\right)_{i, t}+\left(\frac{D V}{T A}\right)_{i, t}+S B_{i, t}+B D V K_{i, t}+F F_{i, t}+ \\
& F B_{i, t}+\varepsilon_{i, t}(2)
\end{aligned}
$$


Tașkin, D., Coșkun, S.

DEÜ SBE Dergisi, Cilt: 17, Sayl: 1

$\left(\frac{U V Y}{T V}\right)_{i, t}=\alpha_{t}+E B H_{i, t}+H A O_{i, t}+\left(\frac{N K}{T S}\right)_{i, t}+\left(\frac{D V}{T A}\right)_{i, t}+A B_{i, t}+B D V K_{i, t}+F F_{i, t}+$ $F B_{i, t}+\varepsilon_{i, t}(3)$

$\left(\frac{U V Y}{T V}\right)_{i, t}=\alpha_{t}+E B H_{i, t}+H A O_{i, t}+\left(\frac{N K}{T A}\right)_{i, t}+\left(\frac{D V}{T A}\right)_{i, t}+S B_{i, t}+B D V K_{i, t}+F F_{i, t}+$ $F B_{i, t}+\varepsilon_{i, t}(4)$

$\left(\frac{K V Y}{T V}\right)_{i, t}=\alpha_{t}+E B H_{i, t}+H A O_{i, t}+\left(\frac{N K}{T S}\right)_{i, t}+\left(\frac{D V}{T A}\right)_{i, t}+A B_{i, t}+B D V K_{i, t}+F F_{i, t}+$ $F B_{i, t}+\varepsilon_{i, t}(5)$

$\left(\frac{K V Y}{T V}\right)_{i, t}=\alpha_{t}+E B H_{i, t}+H A O_{i, t}+\left(\frac{N K}{T A}\right)_{i, t}+\left(\frac{D V}{T A}\right)_{i, t}+S B_{i, t}+B D V K_{i, t}+F F_{i, t}+$ $F B_{i, t}+\varepsilon_{i, t}(6)$

\section{UYGULAMA SONUÇLARI}

Çalışmada 2008-2012 yılları arasında Borsa İstanbul'da işlem gören ve faaliyet konusu enerji olan firmaların finansman kararlarını etkileyen faktörler ve bu faktörler arasında ortaklık yapısının ne derece önemli olduğu panel regresyon analizleri yardımı ile gerçekleştirilmiştir. Panel regresyon analizinde kullanılan modellerin çözümlenmesinde sabit etkiler modeli ile ya da rassal etkiler modeli arasında seçim yapmak için Hausmann testi uygulanmıştır. Teste ilişkin sonuçlar Tablo 2'de sunulmuştur.

Tablo 2: Hausman Test Sonuçları

\begin{tabular}{|l|l|l|l|l|l|l|}
\hline & Model 1 & Model 2 & Model 3 & Model 4 & Model 5 & Model 6 \\
\hline $\begin{array}{l}\text { Yatay Kesit } \\
\text { Rassal Etki } \\
\text { (Olasılık } \\
\text { Değeri) }\end{array}$ & 2.388 & 8.010 & 3.519 & $13.394 *$ & $20.805^{* * *}$ & $20.564 * * *$ \\
& $(0.966)$ & $(0.432)$ & $(0.897)$ & $(0.099)$ & $(0.007)$ & $(0.008)$ \\
\hline
\end{tabular}

$*, * *$ ve $* * *$ sirasıyla $\% 10, \% 5$ ve $\% 1$ düzeyinde istatistiksel anlamlılığ ifade etmektedir.

Tablo 2'de ilk olarak, sınanan yatay kesitte rassal etki vardır boş hipotezine ilişkin Chi-kare değerleri, ardından bu değerlere ilişkin olasılık değerleri yer almaktadır. Rassal etki ile koşulan regresyonlar sonrası ilk 3 modelin rassal etkiler modeline uygun olduğu diğer modellerin ise sabit etkiler yöntemi ile analiz edilmesi gerektiği tespit edilmiştir. $\mathrm{Bu}$ noktadan hareketle hesaplanan panel regresyon analizinin sonuçları Tablo 3'te sunulmuştur. 
Tablo 3: Panel Regresyon Sonuçları

\begin{tabular}{|c|c|c|c|c|c|c|}
\hline & Model 1 & Model 2 & Model 3 & Model 4 & Model 5 & Model 6 \\
\hline Bağımlı Değişken & TB/TV & TB/TV & UVY/TV & UVY/TV & KVY/TV & KVY/TV \\
\hline \multicolumn{7}{|l|}{ Bağımsız Değişkenler } \\
\hline$\overline{\mathrm{EBH}}$ & $\begin{array}{l}0.239 \\
(1.056)\end{array}$ & $\begin{array}{l}0.353^{*} \\
1.850 \\
\end{array}$ & $\begin{array}{l}0.465^{* *} \\
2.391\end{array}$ & $\begin{array}{l}0.663 * * * \\
3.639\end{array}$ & $\begin{array}{l}-0.295^{*} \\
-1.750 \\
\end{array}$ & $\begin{array}{l}-0.267 \\
-1.455 \\
\end{array}$ \\
\hline HAO & $\begin{array}{l}0.239 \\
(0.883)\end{array}$ & $\begin{array}{l}0.174 \\
0.806\end{array}$ & $\begin{array}{l}-0.075^{* *} \\
-2.303\end{array}$ & $\begin{array}{l}0.053 \\
0.517\end{array}$ & $\begin{array}{l}0.351^{*} \\
1.741\end{array}$ & $\begin{array}{l}0.376^{* *} \\
2.223\end{array}$ \\
\hline $\mathrm{NK} / \mathrm{TS}$ & $\begin{array}{l}-4.29 \mathrm{E}-05 \\
(-0.674)\end{array}$ & & \begin{tabular}{|l|}
0.055 \\
0.738 \\
\end{tabular} & & $\begin{array}{l}-3.18 \mathrm{E}-06 \\
-0.079 \\
\end{array}$ & \\
\hline NK/TA & & $\begin{array}{l}-0.632 * * * \\
-3.186 \\
\end{array}$ & & \begin{tabular}{|l|}
$-0.498 * * *$ \\
-4.730 \\
\end{tabular} & & \begin{tabular}{|l|}
-0.074 \\
-1.535 \\
\end{tabular} \\
\hline $\mathrm{DV} / \mathrm{TA}$ & $\begin{array}{l}0.236^{*} \\
(1.834)\end{array}$ & $\begin{array}{l}0.136 \\
1.282\end{array}$ & $\begin{array}{l}0.173^{* * *} \\
2.189\end{array}$ & $\begin{array}{l}0.079 \\
0.679\end{array}$ & $\begin{array}{l}0.041 \\
0.484\end{array}$ & $\begin{array}{l}0.014 \\
0.278\end{array}$ \\
\hline $\mathrm{AB}$ & $\begin{array}{l}0.083 \\
1.606\end{array}$ & & $\begin{array}{l}0.055 \\
0.738\end{array}$ & & $\begin{array}{l}0.031 \\
0.943 \\
\end{array}$ & \\
\hline SB & & $\begin{array}{l}-0.002 \\
-0.358\end{array}$ & & $\begin{array}{l}-0.0005 \\
-0.147\end{array}$ & & $\begin{array}{l}-0.0009 \\
-0.645\end{array}$ \\
\hline BDVK & $\begin{array}{l}0.003 \\
0.027 \\
\end{array}$ & $\begin{array}{l}0.049 \\
0.519\end{array}$ & $\begin{array}{l}-0.042 \\
-1.293 \\
\end{array}$ & \begin{tabular}{|l|}
-0.021 \\
-0.354 \\
\end{tabular} & $\begin{array}{l}0.051 \\
0.744 \\
\end{array}$ & $\begin{array}{l}0.042^{*} \\
1.987 \\
\end{array}$ \\
\hline FF & $\begin{array}{l}-0.557^{*} \\
-1.682 \\
\end{array}$ & \begin{tabular}{|l|}
-0.428 \\
-1.384 \\
\end{tabular} & \begin{tabular}{|l|}
-0.164 \\
-1.497 \\
\end{tabular} & \begin{tabular}{|l|}
-0.044 \\
-0.465 \\
\end{tabular} & $\begin{array}{l}-0.370^{*} \\
-1.783 \\
\end{array}$ & $\begin{array}{l}-0.352 * * * \\
-3.100 \\
\end{array}$ \\
\hline FB & \begin{tabular}{|l}
$0.105^{* * *}$ \\
3.038 \\
\end{tabular} & \begin{tabular}{|l|}
$0.118 * * *$ \\
4.237 \\
\end{tabular} & \begin{tabular}{|l|}
$0.041^{* *}$ \\
2.161 \\
\end{tabular} & $\begin{array}{l}0.052 * * * \\
2.588 \\
\end{array}$ & \begin{tabular}{|l|}
$0.057 * *$ \\
2.206482 \\
\end{tabular} & $\begin{array}{l}0.059 \\
1.096 \\
\end{array}$ \\
\hline Sabit Terim & $\begin{array}{l}-1.336^{* * *} \\
-2.482\end{array}$ & $\begin{array}{l}-1.485 * * * \\
-3.254\end{array}$ & $\begin{array}{l}-0.660 * * \\
-2.108\end{array}$ & $\begin{array}{l}-0.883 * * \\
-2.323\end{array}$ & $\begin{array}{l}-0.566 \\
-1.531\end{array}$ & $\begin{array}{l}-0.594 \\
-0.817\end{array}$ \\
\hline $\mathrm{R}^{2}$ & 0.374 & 0.483 & 0.321 & 0.937 & 0.931 & 0.930 \\
\hline 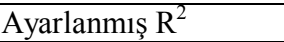 & 0.260 & 0.389 & 0.198 & 0.904 & 0.895 & 0.893 \\
\hline F-Testi & 3.284 & 5.149 & 2.605 & 28.254 & 25.526 & 25.134 \\
\hline F testi Olasıliğ 1 & 0.005 & 0.000 & 0.020 & 0.000 & 0.000 & 0.000 \\
\hline
\end{tabular}

Analiz sonuçlarına baktığımızda 5 modelde de en büyük hissedarın finansal kaldıraç üzerinde istatistiksel olarak anlamlı bir etkiye sahip olduğu görülmektedir. Literatürde de büyük hissedarların yönetim üzerinde kontrol sahibi olduğu çokça vurgulanmakta (Friend ve Lang, 1988; Mehran, 1992) ve genellikle hakim hissedarın kendi getirilerini arttırmaya yönelik olarak uzun dönemli borçları arttırarak firmanın kaldıraç oranını arttırmaya eğilimli olduğu bulunmuştur (Stulz, 1988). Aynı motivasyonla bu çalışmada da en büyük hissedarın toplam borçları (Model 2) ve uzun dönemli borçları (Model 3 ve 4) pozitif yönlü etkilediği, diğer yandan kısa dönemli borçları azaltma eğiliminde olduğu (Model 5) dikkati çekmektedir. Bu durum bize en büyük hissedarın gelirlerini arttırmayı beklerken firmayı kısa dönemli borçlar ile likidite sıkıntısına sokmaktan kaçındığını göstermektedir.

Halka açıklık oranının etkisine baktığımızda uzun dönemli yükümlülükleri negatif yönde etkilediği sonucuna ulaşılmıştır. Bu yatırımcıların pasif oldukları ve firmanın menfaatleri adına yönetim üzerinde söz sahibi olmadığı ile açıklanabilir. Pound (1988) de bu durumun finansal kaldıracı negatif etkileyeceğine değinmiştir. 
Yine aynı şekilde kısa dönemli borçlar ile halka açıklık oranı arasında pozitif yönlü anlamlı ilişkiyi de bu firmaların yatırımcılarının yönetim üzerinde yeterince kontrolü olmaması ile açıklamak mümkündür.

Teminat olarak gösterilebilecek olan duran varlıklar beklendiği şekilde borçları pozitif olarak etkilemektedir. Duran varlıklar toplam aktifler oranının uzun dönemli yükümlülükleri ve toplam borçlara teminat oluşturduğu ve borç verenlere güvence sağladığı görülmektedir.

Karlılık ve finansal kaldıraç arasındaki ilişki literatürde de çokça bulgulanmıştır. Booth vd. (2001) karlı firmaların dağıtılmayan karlar ile finansman ihtiyacını sağlayabileceklerini, bu nedenle dış finansman kaynağına daha az ihtiyaç duyduklarını vurgulamıştır. Bu çalışmada da literatüre paralel olarak net karın toplam aktiflere oranı ile finansal kaldıracı azaltıcı yönde etkilediği görülmüştür. Bu sonuç, finansman hiyerarşisi teorisine de uygunluk göstermektedir.

Borç dışı vergi kalkanının katsayısı genel olarak negatif beklense de, analiz sonuçlarına göre bu etki anlamlı olmasa da uzun dönemli borçları negatif, toplam borçları pozitif etkilemiştir. Kısa dönemli borçları pozitif olarak etkilemesinin nedeni de Wald'ın (1999) çalışmasında olduğu gibi firmaların amortisman düzeylerindeki farklılıktan kaynaklanmaktadır. Tablo 1'e bakıldığında da borç dışı vergi kalkanının standart sapmasının $(0.1348)$, ortalamasından $(0,54)$ çok daha büyük olduğu, bu durum da amortismanın sağlayacağı vergi avantajının, likidite sorunun neden olacağı maliyetlerden daha düşük olduğu ile açıklanabilir.

Farklı ürün ya da hizmetler sunan firmaların farklı üründen kaynaklanan karlar ile sermaye artışları yaşadığı ve borç oranlarında azalmalar yaşandığ 1 görülmüştür (Titman, 1984; Titman ve Wessels, 1988; Berger ve Bonaccorsi di Patti, 2006). Uygulama sonuçlarına göre araştırma geliştirme giderlerinin toplam satışlar içindeki payı firmanın borç oranlarını anlamlı şekilde azaltmaktadır (Model 1, Model 5 ve Model 6).

Firma büyüklügü ise 6 . Model hariç diğer tüm modellerde finansal kaldıraç oranını istatiksel olarak anlamlı düzeyde arttırıcı etkide bulunmaktadır. $\mathrm{Bu}$ bulgu da ödünleşme teorisi ile paralel olarak büyük firmaların küçük firmalara göre daha çeşitli finansman kaynağı kullanması ve iflas riskinin daha az olması nedeni ile küçük firmalara kıyasla daha fazla borçlanabildiği ile açıklanabilir. Diğer yandan satışlardaki ve aktiflerdeki yüzdesel büyüme oranı ile net kar marjı hiç bir modelde anlamlı sonuç vermemiştir.

\section{SONUÇ VE ÖNERILER}

Modigliani ve Miller'ın (1958) finansman kararlarının firma değerini etkilemediği yönündeki teoremleri varsayımları nedeni ile çokça eleştirilmeye başlayınca, finansman kararlarının firma değerine farklı yansımaları olduğunu iddia eden tezler ortaya çıkmıştır. Ödünleşme teorisi, finansman hiyerarşisi teorisi 
ve vekâlet teorisi firmanın finansman ihtiyaçlarına yönelik izlemesi gerektiği stratejilere yön göstermiştir.

Firmalar finansman stratejilerini izlerken finansman kaynaklarına erişim imkan ve maliyetleri dahilinde hareket ederler. Bunun yanında firmanın ortaklık yapısının da finansman kararlarına müdahale etmesi söz konusu olabilir. Firmanın en büyük hissedarı yönetim kurulu kararlarını etkileyecek düzeyde bir paya sahipse bu durumda en büyük hissedarın yönelimleri de finansman kararını şekillendirebilecektir. Ayrıca, firmanın halka açıklık oranı da ortaklığın dağılımını ifade ettiği için yine bu sürece etki edebilecektir.

$\mathrm{Bu}$ bilgilerde hareketle bu çalışma Türkiye için stratejik önem taşıyan enerji alanında faaliyet gösteren ve Borsa İstanbul'da işlem gören firmaların finansman kararlarına etki eden faktörleri ve ortaklık yapısının ayrıca etki edip etmediğini bulmayı amaçlamaktadır. Bu firmaların 2008-2012 yılları arasındaki mali tablolarından derlenen bilgiler ile panel regresyon uygulanıp finansal kaldıracın açıklayıcı değişkenleri olarak karlılık, teminat değeri, büyüme, borç dışı vergi kalkanı, firmanın farklılığı, ortaklık yapısı, en büyük hissedarın payı ve kontrol değişkeni olarak da firma büyüklüğü incelenmiştir.

Çalışmanın sonuçlarına göre beklendiği üzere en büyük hissedarın finansal kaldıracı arttırıcı yönde etkilediği bulunmuştur. En büyük hissedar getirilerini arttırmak adına bu grubun bu sektördeki firmaların borçlarını ve özellikle uzun vadeli borçlarını arttırma eğiliminde oldukları, kısa vadeli yükümlülüklerden ise kaçındıkları dikkati çekmektedir. Halka açıklık oranının ise tam tersi şekilde uzun dönemli borçları ve toplam borçlara negatif yönde etki ettikleri, kısa vadeli yükümlülükleri ise arttırıcı yönde etki ettikleri görülmüştür. Halka açıklık oranı arttıkça firmaların kısa dönemli borçları arttırma eğiliminde olması, ortaklığın yayılması ile firma yönetiminin kontrolü ele geçirip yatırımcıların yönetim üzerinde söz hakkı olmadıkları bir duruma geldiğini işaret etmektedir.

Net kar toplam aktifler arasındaki ilişki de bu çalışmada finansman hiyerarşi teorisine paralellik göstermiş ve karlılık arttıkça finansal kaldıraç kullanımında azalma olduğu sonucuna ulaşılmıştır. Duran varlık miktarının da borç verenler için teminat olarak algılandığı böylelikle uzun dönemli yükümlülükleri ve toplam borçları arttırıcı etkisi olduğu anlaşılmıştır. Borç dışı vergi kalkanının kısa dönemli yükümlülükleri arttırdığı, ürün ve hizmet farklılaşması ile firma farklılığının finansal kaldıracı azalttığı bulunmuştur. Firma büyüklüğünün finansal kaldıracı pozitif yönde etkilediği, bu sonuçtan hareketle büyük firmaların küçük firmalardan daha fazla aktife sahip olmaları ve riski farklı finansman alternatifleri aracılığ 1 ile arttırabildiklerinden borçlanabilme kapasitelerinin daha çok olduğu görülmüştür.

Sonuç olarak çalışmada ortaklık yapılarının firmaların finansman kararlarını etkilediği, bu nedenle hem sermayedarların hem de yasa yapıcıların bu duruma dikkat etmesi gerektiği ortaya çıkmıştır. Büyük hissedarların yönetim 
üzerinde anlamlı bir düzeyde söz sahibi olduğu, bu nedenle bu grubun ellerinde bulunan bu gücü kötüye kullanmayacak şekilde regüle edilmesi gerektiği düşünülmektedir. Bunun yanında borsa yatırımcısının firmayı kısa dönemli yükümlülüklere yöneltmesinin kısa vadede günü kurtarabileceği, uzun dönemde ise firmanın taşıdığı riskleri arttıracağı, enerji gibi önemli bir alanda firmaların risklerine dikkat etmesi zorunluluğu gözden kaçmamalıdır.

\section{KAYNAKÇA}

Akkum, F. (1998). Firmaların uzun dönemli finansman tercihlerinde uygulayabilecekleri finansman hiyerarşisi (pecking order) modeli ve Türkiye üzerine bir araştırma. Yayınlanmamış Doktora Tezi. İstanbul Üniversitesi Sosyal Bilimler Enstitüsü, İstanbul.

Bayraktaroğlu, A. (2010). Mülkiyet yapısı ve finansal performans: İMKB örneği. Ekonomi Bilimleri Dergisi, 2 (2): 11-20.

Berger, A. N. ve Bonaccorsi di Patti, E. (2006). Capital structure and firm performance: A new approach to testing agency theory and an application to the banking industry. Journal of Banking \& Finance, 30 (4): 1065-1102.

Booth, A., Aivazian, V., Demirguc-Kunt, A., ve Maksimovic, V. (2001). Capital structures in developing countries. The Journal of Finance, 56 (1): 87-130.

Brailsford, T. J., Oliver, B. R. ve Pua, S. L. H. (2002). On the relation between ownership structure and capital structure. Journal of Accounting and Finance, 42 (1): 1-26.

Cespedes, J., Gonzalez, M., ve Molina, C. A. (2010). Ownership and capital structure in Latin America. Journal of Business Research, 63 (3): 248-254.

DeAngelo, H. ve Masulis, R. (1980). Optimal capital structure under corporate and personal taxation. Journal of Financial Economics, 8 (1): 3-29.

Driffield, N., Mahambre, V. ve Pal, S. (2007). How does ownership affect capital structure and firm value? Recent evidence from East Asia. CEDI Discussion Paper Series, Working Paper, No: 07-04.

Durukan, M. B. (1997). Hisse senetleri İMKB'de işlem gören firmaların sermaye yapısı üzerine bir araştırma: 1990-1995. IMKB Dergisi, 1 (3): 75-91.

Friend, I. ve Lang, L. (1988). An empirical test of the impact of managerial self-interest on corporate capital structure. Journal of Finance, 43 (2): 271-281.

Jensen, M. ve Meckling, W. (1976). Theory of the firm: Managerial behavior, agency costs and capital structure. Journal of Financial Economics, 3 (4): 305-360. 
Li, K., Yue, H. ve Zhao, L. (2009). Ownership, institutions, and capital structure: Evidence from China. Journal of Comparative Economics, 37 (3): 471490.

Mehran, H., Taggart, R. A. ve Yermack, D. (1999). CEO ownership, leasing, and debt financing. Financial Management, 28 (2): 5-14.

Modigliani, F. ve Miller, M. (1958). The cost of capital, corporation finance and the theory of investment. American Economic Review, 48 (3): 261-275.

Myers, S. C. ve Majluf, N. S. (1984). Corporate financing and investment decisions when firms have information that investors do not have. Journal of Financial Economics, 13 (2): 187-221.

Myers, S. C. (1984). The capital structure puzzle. Journal of Finance, 39 (3): 574-592.

Pound, J. (1988). Proxy contests and the efficiency of shareholder oversight. Journal of Financial Economics, 20 (1-2): 237-265.

Pushner, G. M. (1995). Equity ownership structure, leverage, and productivity: Empirical evidence from Japan. Pacific-Basin Finance Journal, 3 (1): 241-255.

Rajan, R. G. ve Zingales, L. (1995). What do we know about capital structure? Some evidence from international data. Journal of Finance, 50 (5): 1421-1460.

Sayılgan, G., Karabacak, H. ve Küçükkocaoğlu, G. (2006). The firmspecific determinants of corporate capital structure: Evidence from Turkish panel data. Investment Management and Financial Innovations, 3 (2): 125-137.

Sayılgan, G. ve Sayman, Y. (2009). İmalat şirketlerinin ortaklık yapılarının, finansman kararları üzerindeki etkisi: İMKB uygulaması. IMKB Dergisi, 48 (2): 1-11.

Sayılgan, G. ve Uysal, B. (2011). Türkiye Cumhuriyet Merkez Bankas1 sektörel bilançoları kullanılarak sermaye yapısını belirleyen faktörler üzerine bir analiz: 1998-2008. Ankara Üniversitesi SBF Dergisi, 66 (4): 101-124.

Titman, S. (1984). The effect of capital structure on the firms' liquidation decision. Journal of Financial Economics, 13 (1): 137-152.

Titman, S. ve Wessels, R. (1988). The determinants of capital structure choice. Journal of Finance, 43 (1): 1-19.

Wald, J. (1999). How firm characteristics affect capital structure: An international comparison. The Journal of Financial Research, 22 (2): 161-187. 
Tașkin, D., Coșkun, S.

DEÜ SBE Dergisi, Cilt: 17, Sayl: 1

EK: Örneklemdeki Firmalar ve Yıllara Göre Toplam Varlıkları (TL cinsinden)

\begin{tabular}{|l|l|l|l|l|l|}
\hline FíRMA & $\mathbf{2 0 0 8}$ & $\mathbf{2 0 0 9}$ & $\mathbf{2 0 1 0}$ & $\mathbf{2 0 1 1}$ & $\mathbf{2 0 1 2}$ \\
\hline Ak Enerji & 860794685 & 1500870035 & 1913173928 & 2229212046 & 2823507614 \\
\hline Aksa Enerji & - & - & 2384600207 & 2668870595 & 2936023581 \\
\hline Aksu Enerji & 35747198 & 39375527 & 40189057 & 33134567 & 41167820 \\
\hline Ayen Enerji & 525732531 & 495338890 & 493325427 & 909986368 & 960028011 \\
\hline Zorlu Elektrik & 2593063973 & 2414370 & 2611270 & 3409713 & 4984342 \\
\hline İpek Doğal Enerji & 527093626 & 614168994 & 1000645284 & 1609920958 & 2327290 \\
\hline Aygaz & 2464980264 & 2608092029 & 2803648 & 2712123 & 2956255 \\
\hline Omv Petrol & 6935088899 & 6933149010 & 6611301149 & 6620035485 & 6980394 \\
\hline Petkim & 1698292910 & 2113202978 & 2375893103 & 2671127874 & 2799356243 \\
\hline Sasa & 417316 & 390725 & 486966 & 620182 & 683671 \\
\hline Turcas & 520981770 & 517127017 & 561212544 & 860120230 & 1022442516 \\
\hline Tüpraş & 8636798 & 10223304 & 13918037 & 14757986 & 17114140 \\
\hline
\end{tabular}

